\title{
Pipeline Embolization Device for Intracranial Aneurysm: A Systematic Review
}

\author{
G. K. K. Leung • A. C. O. Tsang • W. M. Lui
}

Received: 23 May 2012 / Accepted: 4 October 2012 / Published online: 3 November 2012

(C) The Author(s) 2012. This article is published with open access at Springerlink.com.

\begin{abstract}
Introduction The pipeline embolization device (PED) is a new endovascular stent designed for the treatment of challenging intracranial aneurysms (IAs). Its use has been extended to nonruptured and ruptured IAs of a variety of configurations and etiologies in both the anterior and posterior circulations.

Methods We conducted a systematic review of ten eligible reports on its clinical efficacy and safety.

Results There were 414 patients with 448 IAs. The majority of the IAs were large $(40.2 \%)$, saccular or blister-like $(78.3 \%)$, and were located mostly in the anterior circulation $(83.5 \%)$. The regimens of antiplatelet therapy varied greatly between and within studies. The mean number of the PED used was 2.0 per IA. Deployment was successful in around $95 \%$ of procedures. Aneurysm obliteration was achieved in $82.9 \%$ of IAs at 6 -month. The overall incidences of periprocedural intracranial vascular complication rate and mortality rate were 6.3 and $1.5 \%$, respectively.

Conclusion The PED is a safe and effective treatment for nonruptured IAs. Its use in the context of acute subarachnoid hemorrhage (SAH) should be cautioned. Its main limitations include the need for prolonged antiplatelet therapy, as well as the potential risks of IA rupture and non-IA-related intracerebral hemorrhages (ICH). Future studies should aim at identifying factors that predispose to incomplete obliteration, delayed rupture, and thromboembolic complications.
\end{abstract}

G. K. K. Leung, MBBS, MS $(\bowtie) \cdot$ A. C. O. Tsang, MBBS $\cdot$ W. M. Lui, MBBS

Division of Neurosurgery, Department of Surgery, Li Ka Shing Faculty of Medicine, The University of Hong Kong, Queen Mary Hospital, 102 Pokfulam Road, Hong Kong, China

e-mail: gilberto@hkucc.hku.hk
Keywords Cerebral aneurysm - Endovascular treatment · Flow diverter Pipeline embolization device

\section{Introduction}

Endovascular treatment (EVT) has significantly changed the treatment paradigm of intracranial aneurysms (IAs). Endosaccular embolization with or without device assistance is now a widely adopted treatment modality $[1,2]$. However, a subgroup of lesions, including fusiform [3], wide-necked [4], and large-to-giant aneurysms [5], continues to present with major challenges. Many of these aneurysms have configurations that are unsuitable or unsafe for embolization and/or conventional stenting. Recently, an alternative approach of endoluminal treatment has been developed for these lesions [6]. It involves the use of flow diverters that can disrupt the pulsatile blood flow within an aneurysm sac to the point of stagnation and thrombosis while maintaining flow in the parent artery and side branches. These devices may also facilitate neointimal regrowth and remodeling of the arterial wall. The initial clinical experiences were promising [7-9].

The pipeline embolization device (PED; Covidien Vascular Therapies, Mansfield, MA, USA) is one of the commercially available flow diverters [10]. It is a microcatheter-delivered, self-expanding, cylindrical stent composed of a mesh of 48 individual cobalt chromium and platinum strands. Initially, approved for the treatment of IAs situated between the petrous and the superior hypophyseal segments of the internal carotid artery, its use has now been extended to lesions of various configurations and etiologies in both the anterior and posterior circulations. We present here a systematic literature review on the applications, safety, and clinical efficacy of this therapy. 


\section{Methods}

\section{Search Strategy}

The MEDLINE database was searched for all related articles published in the English language using the following keywords: "aneurysm", "pipeline embolization device", and "flow diverters". These keywords were queried individually or in association. Abstracts were screened for eligibility, and the reference lists of eligible articles were searched for other related studies including on-line documents. The date of the last search was March 21, 2012. We included studies that described the clinical and angiographic outcomes of the PED being used alone or in combination with other modalities. Only reports that consisted of five subjects or more were included. Reports with fewer than five subjects were referred to in the "Discussion" when appropriate.

\section{Data Collection and Analysis}

The selection of articles and the evaluation of study qualities were performed independently by two authors (Gilberto Ka Kit Leung and Anderson Chun On Tsang). There was no disagreement. The system classification proposed by Cook et al. [11] was used to analyze the level of evidence. Data extracted from the eligible studies included the following: characteristics of the IAs (morphology, size, location, clinical presentation, recent rupture, and previous treatment), treatment procedure (antiplatelet and anticoagulating therapies, technical problems during deployment, the number of PEDs used, and adjuvant coiling), symptomatic procedurerelated complication and mortality, aneurysm obliteration and recanalization, in-stent stenosis and migration, as well as functional and symptomatic outcomes. We also studied IAs that had received previous stenting as a subgroup. The procedure for the deployment of the PED was standardized and would not be further elaborated here.

\section{Results}

\section{Description of Studies}

There were ten eligible articles, including seven prospective single-arm cohort studies [9, 12-17], two retrospective uncontrolled case series [18, 19], and one ongoing randomized controlled open-label trial [20]. All completed studies were classified as Level V ("data from anecdotal case series"). Some of the subjects from two eligible studies were also involved in the PED for the Intracranial Treatment of Aneurysms (PITA) trial [16]. The latter was an international multicenter study on 31 subjects from four centers. Six of the 63 IAs reported by Lylyk et al. [9], and eight of the 19 by
Szikora et al. [17] were included in the PITA report. However, the available information did not enable us to separate out these 14 overlapping subjects. We therefore conducted the review based on the total number of IAs reported instead of the actual number of IAs treated. The Pipeline ${ }^{\mathrm{TM}}$ for Uncoilable or Failed Aneurysms Study (PUFS) [12], and the Complete Occlusion of Coilable Aneurysms (COCOA) Clinical Study [20] were conducted under an approved investigational device exemptions (IDE) application of the Food and Drug Administration (FDA), and were available as on-line reports.

We have excluded the report by Deutschmann et al. [21] in which all 12 patients were already included in the PITA report. The report by Puffer et al. [22] only studied specifically the patency of the ophthalmic artery after treatment and was also excluded. As mentioned, we have excluded reports that described fewer than five subjects [7, 23-38].

\section{Characteristics of Aneurysms}

There were 414 patients with 448 IAs, including 374 $(83.5 \%)$ and $74(16.5 \%)$ in the anterior and posterior circulations, respectively. There were 351 (78.3\%) saccular or blister-like, 69 (15.4\%) fusiform, and 28 (6.3\%) dissecting IAs. All except two studies included a mixture of saccular and dissecting/fusiform IAs [18, 20]. Based on 387 IAs with available information, the mean IA size was calculated to be $12.0 \mathrm{~mm}$. The lowest mean IA size per study was $3.8 \mathrm{~mm}$, and the largest was $18.2 \mathrm{~mm}$. There were 171 (38.9\%) small (<10 mm), 177 (40.2\%) large (10-25 mm), and $53(12.1 \%)$ giant $(>25 \mathrm{~mm})$ IAs. The remaining 46 (10.3\%) cases included 38 dissecting IAs and eight saccular IAs which the authors did not further categorize by size [18]. Based on seven studies that described clinical presentations $(n=301)$, the majority of the IAs was asymptomatic ( $n=152$ or $50.1 \%$ ), followed by the presence of mass effect and cranial nerve palsies ( $n=51$ or $16.9 \%$ ). Sixteen (3.6\%) IAs were treated soon after acute subarachnoid hemorrhages (SAHs). Another 37 (8.3\%) IAs had previously ruptured but were not treated in the context of acute SAH. Prior to the placement of the PED, 125 (27.9\%) lesions had received other treatments such as surgical clipping, coiling, and/or stenting (Table 1).

\section{Antiplatelet and Anticoagulating Therapies}

The regimens of antiplatelet therapy and heparinization varied between and within studies. One study did not describe these in details [16]. Before surgery, all patients received aspirin and clopidogrel. These may be started at least 1 day $[13,19], 2$ days $[15,17], 3$ days $[9,18], 5$ days $[13,15]$, or 7 days [12] prior to surgery. The dosage of aspirin ranged from 100 to $150 \mathrm{mg}$, and that of clopidogrel from 75 to 


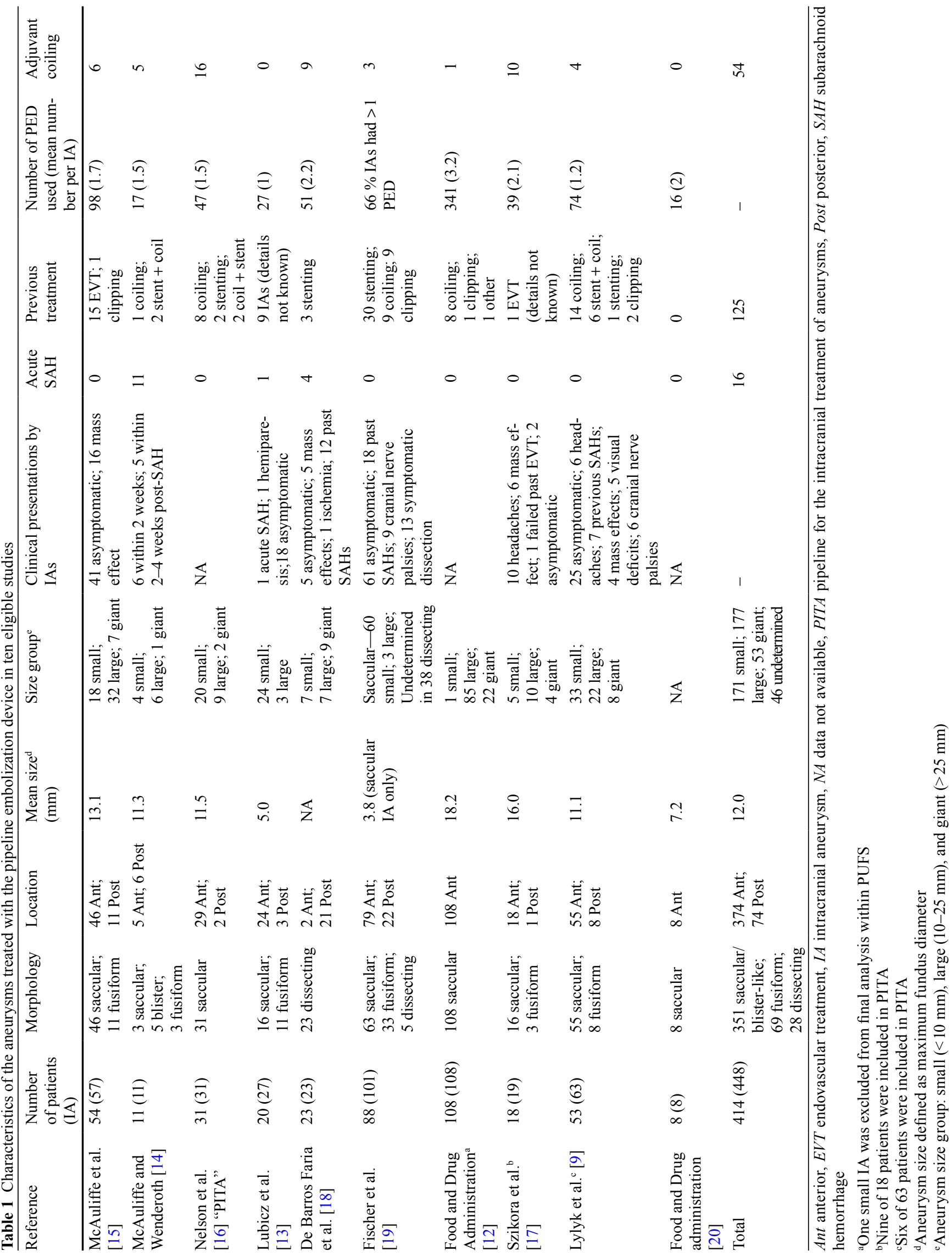


$600 \mathrm{mg}$. Point-of-care platelet inhibition tests were used in some centers [15, 19]. Heparinization was used to achieve an activated clotting time of more than $200 \mathrm{~s}$. This was continued for at least $24 \mathrm{~h}$ post-operatively, except in one study in which heparinization was stopped by the end of the procedure [17]. After surgery, dual antiplatelet agents were continued for at least 3 months although aspirin was commonly continued for another 3 months [9, 12, 18] or even life-long [14]. Six months of dual agents may be used when the PED was covering a side branch [13]. The duration of treatment may also depend on whether the IA affected the anterior (6 months) or the posterior (12 months) circulation $[14,15]$.

\section{PED Placement (Tables 1 and 2)}

More than 811 devices were used to treat 448 IAs; the exact number was not available in one study [19]. Based on the remaining nine studies, the mean number of PED used was 2.0 per IA. The mean number of PED used per study ranged from 1.0 to 3.2 for each IA. Only one study did not employ multiple devices at all [13]. Fifty-four lesions were treated with adjuvant coiling. Technical problems, including failed and suboptimal deployment, occurred during 23 procedures $(5.1 \%)$.

Procedure-Related Complications and Mortalities (Table 2)

We have included complications that were deemed to be procedure-related by the authors of the eligible studies. In analyzing the PUFS, which had an elaborate protocol guiding the reporting of adverse events, we only included those complications defined under the study's "primary safety endpoint" (i.e., the occurrence of major ipsilateral stroke or neurologic death by 180 days after treatment) [12]. From all ten studies, there were three cases of IA ruptures, 14 ischemic events, 11 non-IA-related intracranial hemorrhages, six cases of worsening of mass effect, 11 femoral or retroperitoneal hematomas, and one fatal event of unknown nature. This yielded an overall symptomatic complication rate of $10.3 \%(n=46)$ for 447 IAs. If only intracranial vascular (i.e., ischemic or hemorrhagic) events were included, the complication rate was $6.3 \%(n=28)$. Procedure-related mortalities occurred in nine $(2.2 \%)$ of the 413 patients. The causes of death were due to rebleedings from recently ruptured IAs (two cases) [14], bleeding from previously nonruptured IAs (two cases) [17, 19], ipsilateral intracranial hemorrhage not related to IA (three cases) [12, 20], delayed arterial thrombosis (one case) [19], and one neurologic event of unknown nature [12]. When only previously nonruptured IAs were analyzed $(n=394)$, the major intracranial vascular complication and mortality rates were 6.1 and $0.8 \%$, respectively. For IAs treated in the context of recent
SAH $(n=16)$, the major intracranial vascular complication and mortality rates were 18.8 and $12.5 \%$, respectively.

Angiographic and Clinical Outcomes (Table 2)

Follow-up arrangements varied between and within studies. Eight studies reported angiographic follow-up at 6-month or beyond for a total of 354 IAs. Complete obliteration was achieved in 293 (82.8 \%) lesions. Another study had followup durations ranging from 2 to 6 months, and reported an obliteration rate of $84 \%$ [13]. We also looked at 50 IAs that had previously been treated with conventional stenting. One study treated 30 IAs of these but it was not clear how many had follow-up angiography. The observed obliteration rate was stated as $65 \%$ by the author [19]. Based on the assumption that all had follow-up angiographies, the obliteration rate for this subgroup was $68 \%$ (or 34 in 50 IAs; Table 3). In-stent stenosis or thrombosis on angiograms occurred in 21 cases. Recanalization was uncommon (two cases) although few studies conducted longitudinal followup angiographic studies after confirmed obliteration [12].

Five studies reported clinical outcomes using various parameters. Neurologic deterioration was uncommon among survivors [12]. The majority of patients were asymptomatic and well before surgery and had remained so afterward $[9,12,13,18]$. In one study, symptomatic improvement was reported in $50 \%$ of those with headaches, and in all patients presented with mass effects from their IAs [17].

Fifty IAs were treated with stenting prior to PED placement. Complete obliterations occurred in 34 (68\%). Intracranial vascular complications occurred in five (10\%) of these 50 lesions, compared with $22(5.6 \%)$ in 390 lesions without previous stenting (Table 3 ).

\section{Discussion}

\section{The PED}

Currently, there are two main flow diverters commercially available for use, namely the PED and the SILK flow diverters (SFD, Balt Extrusion, Montmorency, France) [39]. Based on two recent reports, the SILK could achieve a similar IA obliteration rate as the PED (around $80 \%$ ); the former, however, appeared to be associated with a higher early complication rate of around $17 \%$ [40, 41]. Reported studies on SILK are too few to allow for a side-by-side comparison, and we focused only on the PED in the present review. The PED is designed to address several critical problems in the EVT of IAs [2]. With coil embolization, reconstitution of the IAs may occur due to coil compaction. Catheterization of the IAs may potentially cause rupture, and wide-necked 


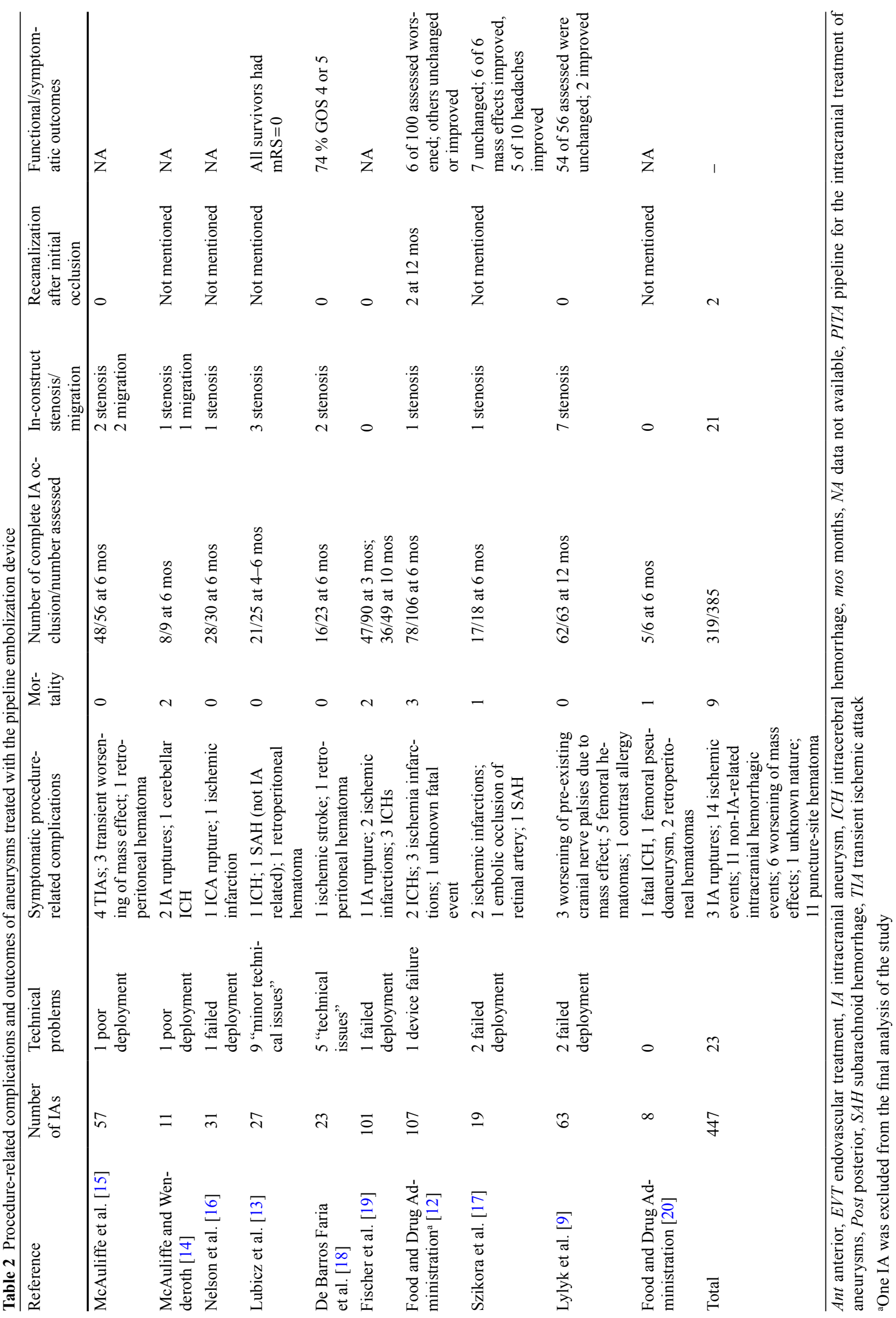


Table 3 Outcome of aneurysms with previous stenting

\begin{tabular}{lccl}
\hline Reference & $\begin{array}{l}\text { Number of } \\
\text { IAs with } \\
\text { previous } \\
\text { stenting }\end{array}$ & $\begin{array}{l}\text { Number of } \\
\text { complete } \\
\text { obliterations }\end{array}$ & $\begin{array}{l}\text { Number of } \\
\text { PED-related } \\
\text { complica- } \\
\text { tions }\end{array}$ \\
\hline $\begin{array}{l}\text { McAuliffe et al. } \\
{[15]}\end{array}$ & 6 & 3 & 0 \\
$\begin{array}{l}\text { McAuliffe and } \\
\text { Wenderoth [14] }\end{array}$ & 2 & 2 & 0 \\
$\begin{array}{l}\text { Fischer et al. [19] } \\
\text { Nelson et al. [17] }\end{array}$ & 2 & $20^{\text {a }}$ & $\begin{array}{l}\text { 2 ischemic } \\
\text { infarctions; } \\
2 \text { ICHs } \\
1 \text { ischemic } \\
\text { infarction } \\
0\end{array}$ \\
$\begin{array}{l}\text { De Barros Faria } \\
\text { et al. [18] }\end{array}$ & 3 & 1 & 0 \\
$\begin{array}{l}\text { Lylyk et al. [9] } \\
\text { Total }\end{array}$ & 7 & 2 & 0 \\
\hline
\end{tabular}

$I A$ intracranial aneurysm, ICH intracerebral hemorrhage, $P E D$ pipeline embolization device

${ }^{a}$ Assuming all patients had follow-up angiographies

IAs may not hold the coils in place despite the use of stent assistance or balloon assistance [42]. The coils also form a permanent mass in the IAs that may potentially worsen any preexisting mass effect. With the PED, there is no manipulation within the IAs, and adjuvant coiling is not necessary though feasible. The PED also has other theoretical advantages. The device forms a scaffold upon which endothelial regrowth can occur, leading to the full coverage of the implant and the aneurysm neck. When compared with selfexpanding or balloon-expandable stents, the PED has higher metal surface area coverage, which greatly facilitates the occlusion of the aneurysm neck and neointimal regrowth. However, the degree to which this neointimal remodeling occurs is unknown, and very late in-stent thrombosis has been known to occur [29]. Ideally, the thrombotic clot within the IAs is reabsorbed by normal healing processes, leading to shrinkage of the IAs, a reduction of mass effect, and a potentially lower risk of recanalization. But even under highly controlled experimental conditions, complete obliteration is by no means the rule [10], and as discussed in the following section, the PED may actually worsen preexisting mass effect. Because of the PED's porosity, outflow in perforators and side branches can be maintained although long-term follow-up data are lacking [10]. Puffer et al. [22] studied the treatment of 20 paraclinoid IAs, and reported that in fact up to a quarter of ophthalmic arteries would undergo proximal thrombosis when covered with the PED. Moreover, whether the PED would be effective for bifurcation IAs or well tolerated in the presence of preexisting perforator stenosis is still unknown.

Based on the reviewed studies, the PED was used mostly for the treatment of IAs that had failed or were considered unsuitable for conventional endosaccular embolization or endoluminal stenting. The majority of the lesions were large, asymptomatic, and saccular IAs situated in the anterior circulation. The need for endoluminal coverage for these relatively large-sized lesions may account for the large number of multiple devices used. Experiences with the PED in the treatment of dissecting IAs were comparatively limited. The available data did not allow a subgroup analysis, which would have been of interest given the different natural histories between saccular and dissecting IAs [14, 15, 18, 19]. De Barros Faria et al. [18] treated 23 dissecting aneurysms with the PED and reported an overall occlusion rate of $87.5 \%$. Good clinical outcome was achieved in $74 \%$ of patients . Individual case reports have also described the successful use of the PED for nonruptured [38] and ruptured [35] dissecting aneurysms. Further studies are needed to investigate the safety and efficacy of this particular application.

\section{Procedure-Related Complications}

Fargen et al. [43] have recently reviewed complications associated with the PED in the treatment of 374 nonruptured IAs. It reported a major complication rate and a mortality rate of 5.3 and $1.3 \%$, respectively. Our review included three additional studies and yielded similar findings. We also included IAs that were treated in the context of acute SAH which is still a matter of controversy [14, 34, 35]. After PED placement, healing of the IAs is delayed while the procedure itself requires antiplatelet and anticoagulating therapies, which can be problematic in the event of a rerupture. We found that two of the 16 recently ruptured IAs rebled soon after treatment and resulted in mortalities. Both reruptured IAs were situated in the anterior circulation while all posterior circulation lesions were treated successfully. The complication and mortality rates for this subgroup were considerably higher than those of nonruptured IAs, but this may partly be due to the small number of cases involved. McAuliffe and Wenderoth [14] suggested the use of adjuvant coiling to secure the aneurysm fundus first, followed by PED placement and the completion of coiling. However, balloon-assisted coiling may not be technically feasible for IAs that incorporate much of the wall of the native vessels for which the PED was indicated in the first place. In any case, there is at present not enough evidence to support the routine use of the PED in the context of a recent rupture. The concern for PED-induced rupture is further heightened by reports of delayed hemorrhages from otherwise silent IAs following PED placement $[23,31,37]$. In our review, we found that two of the four post-PED ruptures involved previously nonruptured IAs. The underlying mechanism was unclear. Mural destabilization and hemodynamic alteration from a PED have been proposed as possible causes [31, 43]. Similarly, delayed ruptures have been reported with the 
SILK diverter [33]. To our knowledge, no predisposing factors have been identified. At present, the small number of ruptured cases precluded meaningful risk analysis.

There were also 11 non-IA-related hemorrhagic complications. The majority $(n=7)$ were intracerebral hemorrhages (ICH) adjacent to or within the dependent territories of the treated arterial segments $[12,13,16,19,20]$. This yielded an incidence of $1.6 \%$ for non-IA-related ICHs within the anterior circulation. The underlying mechanisms were likely to be heterogeneous. Post-PED hemodynamic alterations and hemorrhagic transformation of ischemic infarctions were possible explanations. In addition, IAs with previous stenting had a high rate of vascular complications, possibly due to compromised maneuverability during PED deployment. As with intraluminal stents, thromboembolism is a serious concern after PED placement. Although the use of antiplatelet therapy was universal, the regimens varied greatly in details. Hyporesponsiveness to antiplatelet therapy is a well-recognized phenomenon, and may be associated with coronary stent thrombosis [44] as well as thromboembolic complications during IA embolization [45]. Only a few centers used point-of-care platelet function tests although whether high on-treatment platelet activity contributed to the occurrence of ischemic complications is difficult to ascertain [46]. Interestingly, one study that used point-of-care tests also reported a high incidence of transient ischemic attack but this may be due to an increased alertness and detection bias [15].

The worsening of preexisting mass effects is an interesting finding in that, unless adjuvant coiling is used, the PED does not result in a coil mass and the IAs are supposed to shrink following treatment. Lylyk et al. [9] treated three giant IAs that were causing cranial nerve palsies, and all had postoperative deteriorations despite steroids cover. All eventually improved. McAuliffe et al. [15] treated 16 IAs that were causing mass effects before surgery. The sizes of the lesions were not reported. Eight received steroids cover and three experienced worsening of symptoms. How many of these cases involved coiling was not clear. Inflammatory responses secondary to endosaccular thrombosis were likely to be responsible. Conversely, Szikora et al. [17] treated six IAs with mass effects and all improved after surgery. These findings highlight the importance of collecting solid clinical evidence to support the theoretical advantages of the PED.

\section{Aneurysm Obliteration and Recanalization}

The mechanism of action of the PED does not depend on the size, the configuration, or the dense packing of the aneurysm sac. It is therefore particularly effective for the treatment of some of the challenging IAs. We found an overall obliteration rate of more than $80 \%$ at 6-month, which compares favorably with that of stent-assisted [47] or bal- loon-assisted embolization [48]. Recanalization was also uncommon although there were very few follow-up studies after confirmed obliterations. The IAs in the reviewed series were too heterogeneous and the available information not comprehensive enough to allow the identification of predisposing features of incomplete occlusion. We did, however, found a lower obliteration rate in IAs that had previously undergone stenting procedures. Several authorities suggested that the presence of a stent may reduce the chance of PED-induced obliteration by complicating deployment, impairing the apposition of the stent to the arterial wall and disrupting neointimal remodeling $[9,16]$. This should be taken into considerations during treatment planning for IAs that are potentially suitable for the PED.

\section{Limitations of Study}

It must be emphasized that the majority of the reviewed studies were self-adjudicated single-center studies with varied, relatively short or incomplete follow-ups. This may potentially result in underestimations of the overall complication rate as well as the number of eventual recoveries from initially unfavorable outcomes. For instance, in the PUFS, some cases of hemorrhagic complications did not reach primary endpoints and were therefore not included in our analysis. Both the PUFS and COCOA reports consisted of only on-line documents based on a company-driven registry, and their results should be considered with care [12]. Furthermore, two studies had patients that overlapped with those in the PITA which may affect the accuracy of our analysis.

\section{Conclusions}

The PED is a feasible, effective, and safe method for the endoluminal treatment of nonruptured IAs. Its use in the treatment of recently ruptured IAs is associated with a relatively high rate of rebleeding and should be cautioned. Previous stenting may also result in poorer outcome. Recanalization after complete obliteration, in-stent stenosis and thrombosis are uncommon. The main limitations of the PED include the need for prolonged antiplatelet therapy, and the potential risks of delayed rupture, non-IA-related ICH, worsening of preexisting mass effect, and reduced efficacy with previous stenting. Flow-diverting devices represent an important advancement in the treatment of IAs although many of the theoretical advantages of the PED such as aneurysm shrinkage and neointimal remodeling are yet to be proven experimentally or clinically. Randomized studies comparing the PED with conventional EVT are methodologically difficult since each modality has its unique indications in terms of IA characteristics. Future studies may aim at identifying fac- 
tors that predispose to incomplete occlusion, PED-induced rupture, and thromboembolic complications.

Acknowledgments None.

Previous Presentation/Publication None.

Conflict of Interest The authors have no funding or any potential conflict of interest to declare.

Open Access This article is distributed under the terms of the Creative Commons Attribution License which permits any use, distribution, and reproduction in any medium, provided the original author(s) and the source are credited.

\section{References}

1. Ferns SP, Sprengers ME, van Rooij WJ, Rinkel GJ, van Rijn JC, Bipat S, et al. Coiling of intracranial aneurysms: a systematic review on initial occlusion and reopening and retreatment rates. Stroke. 2009;40(8):e523-9.

2. Seibert B, Tummala RP, Chow R, Faridar A, Mousavi SA, Divani AA. Intracranial aneurysms: review of current treatment options and outcomes. Front Neurol. 2011;2:45.

3. Lubicz B, Collignon L, Lefranc F, Bruneau M, Brotchi J, Baleriaux D, et al. Circumferential and fusiform intracranial aneurysms: reconstructive endovascular treatment with self-expandable stents. Neuroradiology. 2008;50(6):499-507.

4. Pierot L, Cognard C, Anxionnat R, Ricolfi F. Endovascular treatment of ruptured intracranial aneurysms: factors affecting midterm quality anatomic results: analysis in a prospective, multicenter series of patients (CLARITY). AJNR Am J Neuroradiol. 2012;33(8):1475-80. doi:10.3174/ajnr.A3003.

5. Gonzalez NR, Duckwiler G, Jahan R, Murayama Y, Vinuela F. Challenges in the endovascular treatment of giant intracranial aneurysms. Neurosurgery. 2008;62(6 Suppl 3):1324-35.

6. Pierot L. Flow diverter stents in the treatment of intracranial aneurysms: where are we? J Neuroradiol. 2011;38(1):40-6.

7. Fiorella D, Kelly ME, Albuquerque FC, Nelson PK. Curative reconstruction of a giant midbasilar trunk aneurysm with the pipeline embolization device. Neurosurgery. 2009;64(2):212-7 (discussion 7).

8. Fiorella D, Woo HH, Albuquerque FC, Nelson PK. Definitive reconstruction of circumferential, fusiform intracranial aneurysms with the pipeline embolization device. Neurosurgery. 2008;62(5):1115-20 (discussion 20-1).

9. Lylyk P, Miranda C, Ceratto R, Ferrario A, Scrivano E, Luna HR, et al. Curative endovascular reconstruction of cerebral aneurysms with the pipeline embolization device: the Buenos Aires experience. Neurosurgery. 2009;64(4):632-42 (discussion 42-3; quiz N6).

10. Kallmes DF, Ding YH, Dai D, Kadirvel R, Lewis DA, Cloft HJ. A new endoluminal, flow-disrupting device for treatment of saccular aneurysms. Stroke. 2007;38(8):2346-52.

11. Cook DJ, Guyatt GH, Laupacis A, Sackett DL. Rules of evidence and clinical recommendations on the use of antithrombotic agents. Chest. 1992;102(4 Suppl):305S-11S.

12. Food and Drug Administration. Summary of safety and effectivenss data. PED. 2012. http://www.accessdata.fda.gov/scripts/ $\mathrm{cdrh} / \mathrm{cfdocs} / \mathrm{cftopic} / \mathrm{pma} / \mathrm{pma} . \mathrm{cfm}$ ?num $\pi=$. Accessed 18 Aug 2012.
13. Lubicz B, Collignon L, Raphaeli G, De Witte O. Pipeline flowdiverter stent for endovascular treatment of intracranial aneurysms: preliminary experience in 20 patients with 27 aneurysms. World Neurosurg. 2011;76(1-2):114-9.

14. McAuliffe W, Wenderoth JD. Immediate and midterm results following treatment of recently ruptured intracranial aneurysms with the pipeline embolization device. AJNR Am J Neuroradiol. 2012;33:487-93.

15. McAuliffe W, Wycoco V, Rice H, Phatouros C, Singh TJ, Wenderoth $\mathrm{J}$. Immediate and midterm results following treatment of unruptured intracranial aneurysms with the pipeline embolization device. AJNR Am J Neuroradiol. 2012;33(1):164-70.

16. Nelson PK, Lylyk P, Szikora I, Wetzel SG, Wanke I, Fiorella D. The pipeline embolization device for the intracranial treatment of aneurysms trial. AJNR Am J Neuroradiol. 2011;32(1):34-40.

17. Szikora I, Berentei Z, Kulcsar Z, Marosfoi M, Vajda ZS, Lee W, et al. Treatment of intracranial aneurysms by functional reconstruction of the parent artery: the Budapest experience with the pipeline embolization device. AJNR Am J Neuroradiol. 2010;31(6):1139-47.

18. de Barros Faria M, Castro RN, Lundquist J, Scrivano E, Ceratto $\mathrm{R}$, Ferrario A, et al. The role of the pipeline embolization device for the treatment of dissecting intracranial aneurysms. AJNR Am J Neuroradiol. 2011;32(11):2192-5.

19. Fischer S, Vajda Z, Aguilar Perez M, Schmid E, Hopf N, Bazner $\mathrm{H}$, et al. Pipeline embolization device (PED) for neurovascular reconstruction: initial experience in the treatment of 101 intracranial aneurysms and dissections. Neuroradiology. 2012;54:369-82.

20. Food and Drug Administration. COCOA 2010 Annual Report. 2010. http://www.fda.gov/downloads/AdvisoryCommittees/ CommitteesMeetingMaterials/MedicalDevices/MedicalDevicesAdvisoryCommittee/NeurologicalDevicesPanel/UCM247158. pdf. Accessed 18 Aug 2012.

21. Deutschmann HA, Wehrschuetz M, Augustin M, Niederkorn K, Klein GE. Long-term follow-up after treatment of intracranial aneurysms with the pipeline embolization device: results from a single center. AJNR Am J Neuroradiol. 2011;33:481-6.

22. Puffer RC, Kallmes DF, Cloft HJ, Lanzino G. Patency of the ophthalmic artery after flow diversion treatment of paraclinoid aneurysms. J Neurosurg. 2012;116:892-6.

23. Cebral JR, Mut F, Raschi M, Scrivano E, Ceratto R, Lylyk P, et al. Aneurysm rupture following treatment with flow-diverting stents: computational hemodynamics analysis of treatment. AJNR Am J Neuroradiol. 2011;32(1):27-33.

24. Chan TT, Chan KY, Pang PK, Kwok JC. Pipeline embolisation device for wide-necked internal carotid artery aneurysms in a hospital in Hong Kong: preliminary experience. Hong Kong Med J. 2011;17(5):398-404.

25. Chow M, McDougall C, O'Kelly C, Ashforth R, Johnson E, Fiorella D. Delayed spontaneous rupture of a posterior inferior cerebellar artery aneurysm following treatment with flow diversion: a clinicopathologic study. AJNR Am J Neuroradiol. 2012;33:E46-51.

26. Consoli A, Nappini S, Renieri L, Limbucci N, Ricciardi F, Mangiafico S. Treatment of two blood blister-like aneurysms with flow diverter stenting. J Neurointerv Surg. 2012;4:e4.

27. Consoli A, Renieri L, Nappini S, Ricciardi F, Grazzini G, Scarpini G, et al. Endovascular treatment with 'kissing' flow diverter stents of two unruptured aneurysms at a fenestrated vertebrobasilar junction. J Neurointerv Surg. 2012. doi:10.1136/ neurintsurg-2011-010188.

28. Fiorella D, Albuquerque F, Gonzalez F, McDougall CG, Nelson PK. Reconstruction of the right anterior circulation with the Pipeline embolization device to achieve treatment of a progressively symptomatic, large carotid aneurysm. J Neurointerv Surg. 2010;2(1):31-7. 
29. Fiorella D, Hsu D, Woo HH, Tarr RW, Nelson PK. Very late thrombosis of a pipeline embolization device construct: case report. Neurosurgery. 2010;67(3 Suppl Operative):onsE313-4 (discussion onsE4).

30. Fiorella D, Lylyk P, Szikora I, Kelly ME, Albuquerque FC, McDougall CG, et al. Curative cerebrovascular reconstruction with the Pipeline embolization device: the emergence of definitive endovascular therapy for intracranial aneurysms. J Neurointerv Surg. 2009;1(1):56-65.

31. Hampton T, Walsh D, Tolias C, Fiorella D. Mural destabilization after aneurysm treatment with a flow-diverting device: a report of two cases. J Neurointerv Surg. 2011;3(2):167-71.

32. Kulcsar Z, Houdart E, Bonafe A, Parker G, Millar J, Goddard AJ, et al. Intra-aneurysmal thrombosis as a possible cause of delayed aneurysm rupture after flow-diversion treatment. AJNR Am J Neuroradiol. 2011;32(1):20-5.

33. Kulcsar Z, Wetzel SG, Augsburger L, Gruber A, Wanke I, Rufenacht DA. Effect of flow diversion treatment on very small ruptured aneurysms. Neurosurgery. 2010;67(3):789-93.

34. Martin AR, Cruz JP, Matouk CC, Spears J, Marotta TR. The pipeline flow-diverting stent for exclusion of ruptured intracranial aneurysms with difficult morphologies. Neurosurgery. 2012;70(1 Suppl Operative):21-8.

35. Narata AP, Yilmaz H, Schaller K, Lovblad KO, Pereira VM. Flow diverter stent for ruptured intracranial dissecting aneurysm of vertebral artery. Neurosurgery. 2012;70:982-8.

36. Van Rooij WJ, Sluzewski M. Perforator infarction after placement of a pipeline flow-diverting stent for an unruptured A1 aneurysm. AJNR Am J Neuroradiol. 2010;31(4):E43-4.

37. Velat GJ, Fargen KM, Lawson MF, Hoh BL, Fiorella D, Mocco J. Delayed intraparenchymal hemorrhage following pipeline embolization device treatment for a giant recanalized ophthalmic aneurysm. J Neurointerv Surg. 2011;4(5):e24. doi:10.1136/ neurintsurg-2011-010129.

38. Yeung TW, Lai V, Lau HY, Poon WL, Tan CB, Wong YC. Longterm outcome of endovascular reconstruction with the Pipeline embolization device in the management of unruptured dissecting aneurysms of the intracranial vertebral artery. J Neurosurg. 2012;116(4):882-7.
39. Byrne JV, Beltechi R, Yarnold JA, Birks J, Kamran M. Early experience in the treatment of intra-cranial aneurysms by endovascular flow diversion: a multicentre prospective study. PLoS One. 2010;5:e12492.

40. Pistocchi S, Blanc R, Bartolini B, Piotin M. Flow diverters at and beyond the level of the circle of willis for the treatment of intracranial aneurysms. Stroke. 2012;43(4):1032-8.

41. Wagner A, Cortsen M, Hauerberg J, Romner B, Wagner MP. Treatment of intracranial aneurysms. Reconstruction of the parent artery with flow-diverting (Silk) stent. Neuroradiology. 2012;54(7):709-18.

42. Aletich VA, Debrun GM, Misra M, Charbel F, Ausman JI. The remodeling technique of balloon-assisted Guglielmi detachable coil placement in wide-necked aneurysms: experience at the University of Illinois at Chicago. J Neurosurg. 2000;93(3):388-96.

43. Fargen KM, Velat GJ, Lawson MF, Mocco J, Hoh BL. A review of reported complications associated with the pipeline embolization device. World Neurosurg. 2012; 77(3-4):403-4. doi:10.1016/j. wneu.2012.02.038.

44. Sambu N, Radhakrishnan A, Dent H, Calver AL, Corbett S, Gray $\mathrm{H}$, et al. Personalised antiplatelet therapy in stent thrombosis: observations from the clopidogrel resistance in stent thrombosis (CREST) registry. Heart. 2012;98(9):706-11.

45. Haraguchi K, Miyachi S, Izumi T, Matsubara N, Naito T, Asai T, et al. Resistance to antiplatelet agents assessed by a point-of-care platelet function test and thromboembolic adverse events in neurointervention. No Shinkei Geka. 2012;40(5):399-406.

46. Lee DH, Arat A, Morsi H, Shaltoni H, Harris JR, Mawad ME. Dual antiplatelet therapy monitoring for neurointerventional procedures using a point-of-care platelet function test: a single-center experience. AJNR Am J Neuroradiol. 2008;29(7):1389-94.

47. Bodily KD, Cloft HJ, Lanzino G, Fiorella DJ, White PM, Kallmes DF. Stent-assisted coiling in acutely ruptured intracranial aneurysms: a qualitative, systematic review of the literature. AJNR Am J Neuroradiol. 2011;32(7):1232-6.

48. Shapiro M, Babb J, Becske T, Nelson PK. Safety and efficacy of adjunctive balloon remodeling during endovascular treatment of intracranial aneurysms: a literature review. AJNR Am J Neuroradiol. 2008;29(9):1777-81. 